Article

\title{
Cytotoxicity of $\beta$-Cyclodextrins in Retinal Explants for Intravitreal Drug Formulations
}

\author{
Manisha Prajapati ${ }^{1}$, Gustav Christensen ${ }^{2}$, François Paquet-Durand ${ }^{2}$ and Thorsteinn Loftsson ${ }^{1, * \mathbb{D}}$ \\ 1 Faculty of Pharmaceutical Sciences, University of Iceland, Hofsvallagata 53, IS-107 Reykjavik, Iceland; \\ map52@hi.is \\ 2 Institute for Ophthalmic Research, University of Tübingen, Elfriede-Aulhorn-Strasse 5-7, \\ 72076 Tübingen, Germany; gustav.christensen@uni-tuebingen.de (G.C.); \\ francios.paquet-durand@klinikum.uni-tuebingen.de (F.P.-D.) \\ * Correspondence: thorstlo@hi.is; Tel.: +354-525-4464; Fax: +354-525-4071
}

Citation: Prajapati, M.; Christensen,

G.; Paquet-Durand, F.; Loftsson, T. Cytotoxicity of $\beta$-Cyclodextrins in Retinal Explants for Intravitreal Drug Formulations. Molecules 2021, 26, 1492. https://doi.org/10.3390/ molecules26051492

Academic Editor: Marina Isidori

Received: 15 February 2021

Accepted: 3 March 2021

Published: 9 March 2021

Publisher's Note: MDPI stays neutral with regard to jurisdictional claims in published maps and institutional affiliations.

Copyright: (c) 2021 by the authors. Licensee MDPI, Basel, Switzerland. This article is an open access article distributed under the terms and conditions of the Creative Commons Attribution (CC BY) license (https:// creativecommons.org/licenses/by/ $4.0 /)$.

\begin{abstract}
Cyclodextrins (CDs) have been widely used as pharmaceutical excipients for formulation purposes for different delivery systems. Recent studies have shown that CDs are able to form complexes with a variety of biomolecules, such as cholesterol. This has subsequently paved the way for the possibility of using CDs as drugs in certain retinal diseases, such as Stargardt disease and retinal artery occlusion, where CDs could absorb cholesterol lumps. However, studies on the retinal toxicity of CDs are limited. The purpose of this study was to examine the retinal toxicity of different beta- $(\beta) C D$ derivatives and their localization within retinal tissues. To this end, we performed cytotoxicity studies with two different CDs-2-hydroxypropyl- $\beta C D(H P \beta C D)$ and randomly methylated $\beta$-cyclodextrin (RM $\beta C D$ ) - using wild-type mouse retinal explants, the terminal deoxynucleotidyl transferase dUTP nick end labeling (TUNEL) assay, and fluorescence microscopy. RM $\beta C D$ was found to be more toxic to retinal explants when compared to $\mathrm{HP} \beta \mathrm{CD}$, which the retina can safely tolerate at levels as high as $10 \mathrm{mM}$. Additionally, studies conducted with fluorescent forms of the same CDs showed that both CDs can penetrate deep into the inner nuclear layer of the retina, with some uptake by Müller cells. These results suggest that HP $\beta C D$ is a safer option than RM $\beta C D$ for retinal drug delivery and may advance the use of CDs in the development of drugs designed for intravitreal administration.
\end{abstract}

Keywords: cyclodextrin; retinal explant; cytotoxicity; uptake

\section{Introduction}

Cyclodextrins (CDs) are cyclic oligosaccharides consisting of $(\alpha-1,4-)$-linked $\alpha-\mathrm{D}$ glucopyranose units with a hydrophobic central cavity and a hydrophilic outer surface. They can form water-soluble inclusion complexes with numerous lipophilic drugs provided that their structure (or part of it) fits in the CD cavity. No covalent bonds are formed or broken during the complexation and drug molecules in the complex are in rapid equilibria with free molecules in the aqueous complexation media [1]. The complexation affects many physicochemical properties of drugs, such as their aqueous solubility and chemical stability [2]. Natural CDs (i.e., $\alpha C D, \beta C D$, and $\gamma C D$ ) have a limited solubility in water and, thus, CD derivatives with an improved solubility have been synthesized and are currently used as solubilizing complexing agents in various marketed pharmaceutical products, particularly 2-hydroxypropyl- $\beta$-cyclodextrin (HP $\beta C D$ ) and sulfobutylether- $\beta$-cyclodextrin $(\mathrm{SBE} \beta \mathrm{CD})$, as well as randomly methylated $\beta$-cyclodextrin $(\mathrm{RM} \beta C D)$, although to a lesser extent [1]. CDs have also undergone extensive safety studies and have been approved by both the European Medicines Agency (EMA) and the Food and Drug Administration (FDA) for pharmaceutical use and in dietary supplements $[3,4]$. CDs have been the subject of numerous review publications [5-13]. 
Drugs for the treatment of retinal diseases are most often delivered via intravitreal injections or implants, where the drug is administered directly into the vitreous humor, which is the hydrogel-type fluid that occupies the space between the lens and the retina. The vitreous mainly consists (99\%) of water in a network of collagen and hyaluronic acid. In humans, the volume of the vitreous humor is about $4 \mathrm{~mL}$ [14]. Drug molecules must be dissolved in the aqueous vitreous to permeate into the retinal tissue. After an intravitreal injection, hydrophilic and high molecular weight drugs (e.g., proteins and peptides) are known to be excreted via an anterior route to the aqueous humor, while small lipophilic drugs easily pass the retina and are removed via the posterior choroidal flow [15]. The half-life of a dissolved drug in the vitreous humor is typically less than 10 to $24 \mathrm{~h}$, where small molecules have a shorter half-life than biomolecules such as proteins $[16,17]$. It is expected that the hydrophilic CD molecules (molecular weight between about 1000 and $2000 \mathrm{Da}$ ) are readily removed from the vitreous humor after an intravitreal injection. CDs might be able to enhance the retinal delivery of poorly soluble lipophilic drugs after intravitreal administration.

The ability of CDs to complex biomolecules depends upon the molecular structure and the $\mathrm{CD}$ binding constants and generally follows the order carbohydrates $<<$ nucleic acids $<<$ proteins $<$ lipids [18]. Therefore, most biological effects of CDs are based on their interaction with membranes rich in lipids and their ability to extract lipids (e.g., phospholipids and cholesterol) from the plasma membrane [18]. In ophthalmic drug delivery, CDs have mainly been applied topically to the eye, with little or no reports on their intravitreal administration [19-21]. Although hydrophilic CDs, such as HP $\beta C D$ and SBE $\beta C D$, have been shown to be well-tolerated when applied topically to the eye, with no detectable side effects, their parent $\beta C D$ and $R M \beta C D$ are known to extract cholesterol from cell membranes and form cholesterol/CD complexes [22-24]. Furthermore, Nociari et al. observed that $\beta C D$ extracted lipofuscin bisretinoids from the retinal pigment epithelium (RPE) [25]. Based on these observations, it was proposed that CDs can be used to develop therapeutic candidates for many retinal degenerative diseases, such as Stargardt disease, which is an inherited form of macular degeneration causing central vision loss and sometimes referred to as juvenile macular degeneration. The cause of Stargardt disease is characterized by an abnormal accumulation of lipofuscin in the retina [26]. Similarly, the topical administration of $\mathrm{HP} \beta C D$ as eye drops over 3 months has shown a significant efficacy in reducing amyloid-beta and inflammation in aged mouse retina, consequently improving the retinal function by elevating retinal pigment epithelium-specific protein 65 (RPE 65), which is a key molecule in the visual cycle [27]. Even oral HP $\beta C D$ treatment in mice resulted in a reduction in the retinal cholesterol content and changes in the retinal sterol, gene, and protein levels [28].

Our study aimed to examine the cytotoxicity of CDs in mouse retinal explants using $\beta C D$ derivatives to explore their applicability for future ophthalmic formulations. Additionally, fluorophore-conjugation to the same CDs was used to trace the uptake and localization within the retina (Figure 1). 
(a)

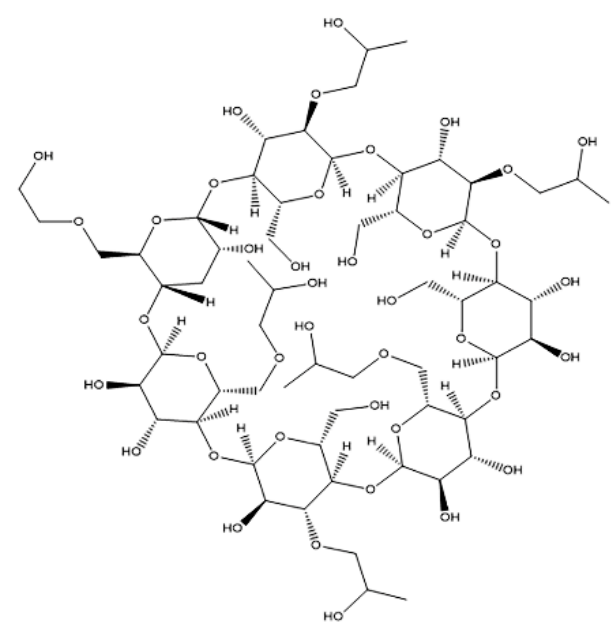

(c)

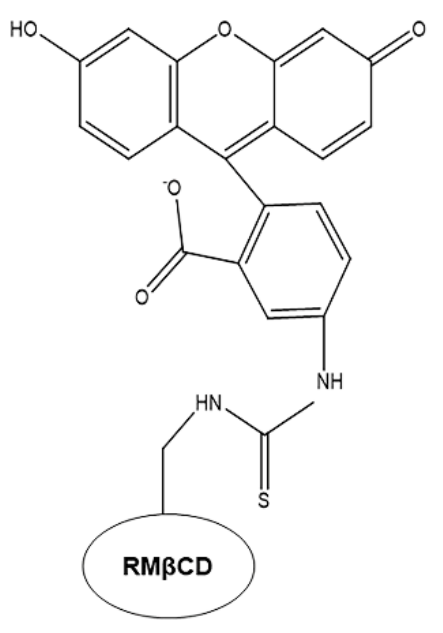

(b)

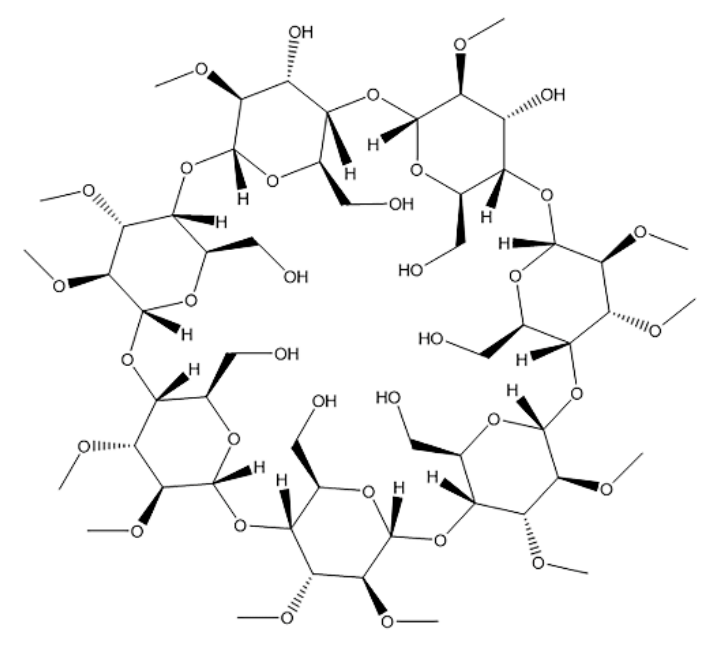

(d)

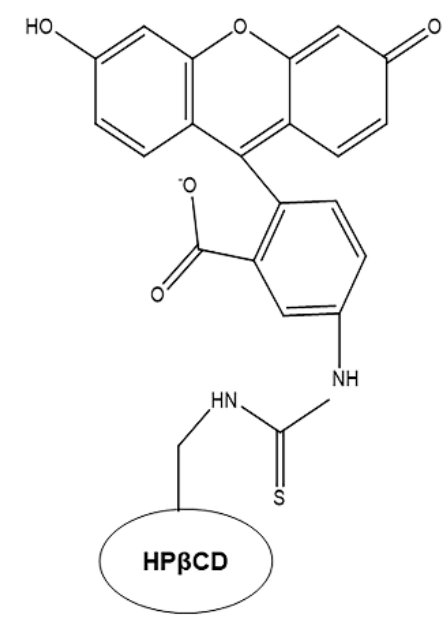

(e)

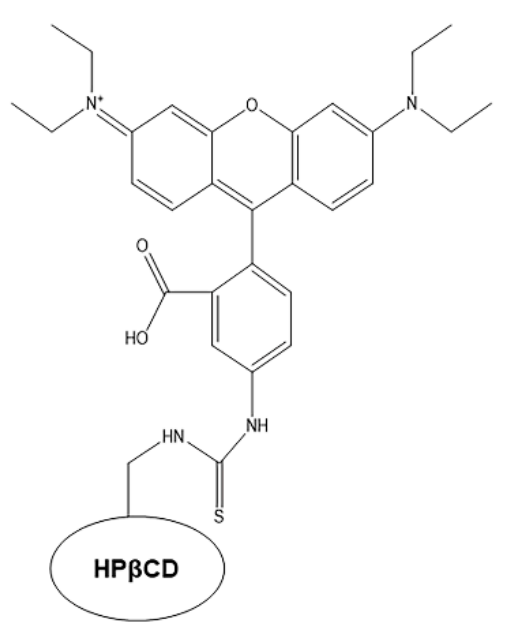

Figure 1. Chemical structures of (a) 2-hydroxypropyl- $\beta$-cyclodextrin (HP $\beta C D)$, (b) randomly methylated $\beta$ cyclodextrin (RM $\beta C D)$, (c) 6-deoxy-6-[(5/6)-fluoresceinylthioureido]-HP $\beta C D$ (FITC-RM $\beta C D)$, (d) 6-deoxy-6-[(5/6)fluoresceinylthioureido]-RM $\beta C D(F I T C-H P \beta C D)$, and (e) 6-deoxy-6-[(5/6)-rhodaminylthioureido]-HP $\beta C D$ (RBITC$\mathrm{HP} \beta \mathrm{CD})$.

\section{Results and Discussion}

\subsection{Particle Size and TEM Data Analysis}

The particle size of $100 \mathrm{mM}$ CD aggregates was measured by Nano Sight and confirmed by Transmission Electron Microscopy (TEM) (Figure 2). CDs tend to form nano-sized aggregates when their concentration is increased [29]. Although the aggregation in pure aqueous $\mathrm{CD}$ solutions is generally low, the aggregation is frequently enhanced by the formation of drug/CD complexes. Furthermore, the aggregation and the size of the aggregates increase with an increasing CD concentration [30]. 
(a)

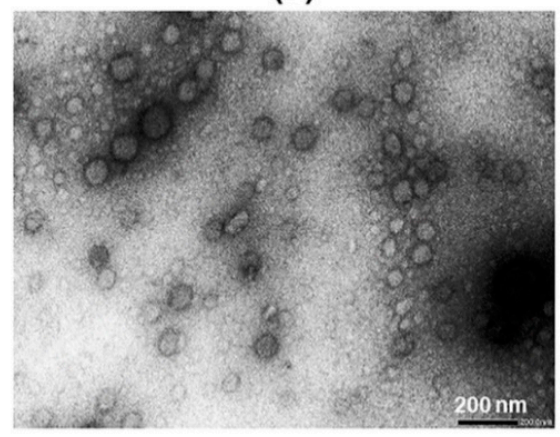

(b)

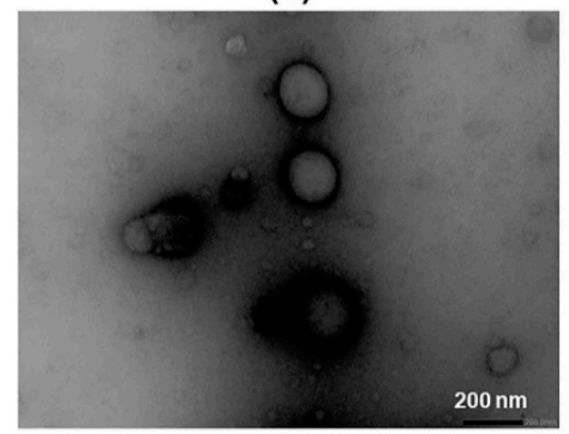

Figure 2. Transmission electron microscopy images of cyclodextrin (CD) aggregates at a magnitude of $30 \mathrm{~K}$. (a) $100 \mathrm{mM} \mathrm{HP} \beta C D$ and (b) $100 \mathrm{mM}$ RM $\beta C D$. The average diameter of RM $\beta C D$ aggregates appeared to be around two times larger than that of HP $\beta C D$.

The concentration of CDs used in pharmaceutical formulations depends on the type of CD used, but due to their favorable toxicological and pharmacological profiles, the $\mathrm{CD}$ concentrations can be relatively high [31]. However, the limited solubility of the natural CDs, especially $\beta C D$, can limit their concentration [1]. Both HP $\beta C D$ and $R M \beta C D$ are very soluble in water (Section 3.1), so we used very high concentrations of these $\mathrm{CD}$ derivatives to observe their potential toxicity on retinal explants. Aggregates were observed in aqueous $\mathrm{HP} \beta C D$ and $\mathrm{RM} \beta C D$ solutions. The average diameter of the HP $\beta C D$ aggregate, as determined by Nano Sight, was $148 \mathrm{~nm}$ and that of RM $\beta C D$ was $305 \mathrm{~nm}$. Larger aggregates (diameter $>100 \mathrm{~nm}$ ) do not have a spherical shape like smaller ones $(<100 \mathrm{~nm})$. Instead, they look like clusters of smaller, spherically-shaped aggregates [32]. The aggregate diameters observed with TEM are smaller than those determined by Nano Sight. This can be explained by the TEM sample preparation, where the aggregate size or structure can change during sample preparation.

Generally, it is thought that only the free drug molecules, which have dissociated from the CD complex, are able to permeate cell membranes [1]. However, recent findings have revealed that $\mathrm{CD}$ molecules can enter the cells by endocytosis [33] and this may also be true for drug/CD complexes [34]. However, it appears highly unlikely that the large and hydrophilic CD aggregates can enter cells.

\subsection{Cytotoxicity of $\beta$-Cyclodextrin Derivatives in Retinal Explant Cultures}

The terminal deoxynucleotidyl transferase dUTP nick end labeling (TUNEL) assay was employed to quantify the number of dying cells in histological sections from retinal explant cultures incubated with CDs (Figure 3).

The relative cytotoxicity of the CDs was expressed as the percentage of TUNEL positive cells in the respective part of the retinal tissue section. They were counted in both the outer retina (outer nuclear layer, ONL) and inner retina (inner nuclear layer, INL) (Figure 3a). TUNEL positive cells were not counted in the ganglion cell layer (GCL) as most of the cells typically degenerate quickly after explant tissue preparation due to the cutting of the optic nerve.

10 and $100 \mathrm{mM}$ CDs were applied on top of the retinal cultures, i.e., the side closest to the GCL, which is the route the CDs would naturally follow after an intravitreal injection. For $100 \mathrm{mM}$, the TUNEL positive cell values in the INL were about $0.5 \%, 5 \%$, and $0.6 \%$ for the control, RM $\beta C D$, and $\mathrm{HP} \beta C D$, respectively, while for the ONL, they were about $3 \%$, $12 \%$, and $6 \%$ for the control, RM $\beta C D$, and $\mathrm{HP} \beta C D$, respectively (Figure $3 \mathrm{~b}$ ). Therefore, both types of CDs were toxic compared to the control when used in $100 \mathrm{mM}$ concentrations. RM $\beta C D$ was significantly more toxic compared to HP $\beta C D$, both in INL and ONL. HP $\beta C D$ was predominantly toxic to ONL cells, i.e., where the cell bodies of photoreceptors are located. At the $10 \mathrm{mM}$ concentration, $\mathrm{RM} \beta \mathrm{CD}$ still exhibited significant toxicity and killed cells in both ONL and INL, while the number of TUNEL positive cells for HP $\beta C D$ was 
similar to the control. This demonstrated that the retina could safely tolerate levels as high as $10 \mathrm{mM} \mathrm{HP} \beta \mathrm{CD}$.

(a)
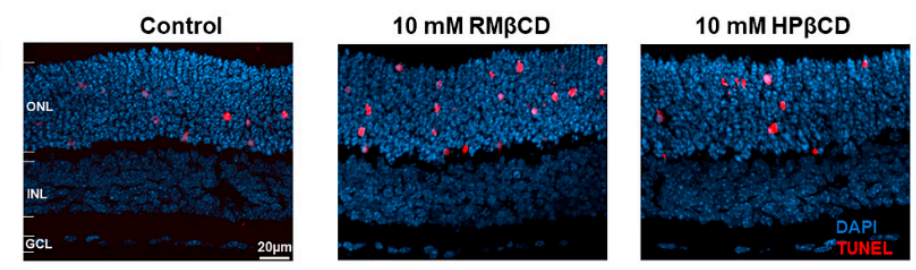

$100 \mathrm{mM}$ RM $\beta C D$

100 mM HP $\beta C D$
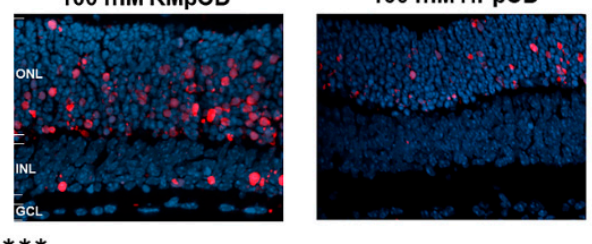

(b)

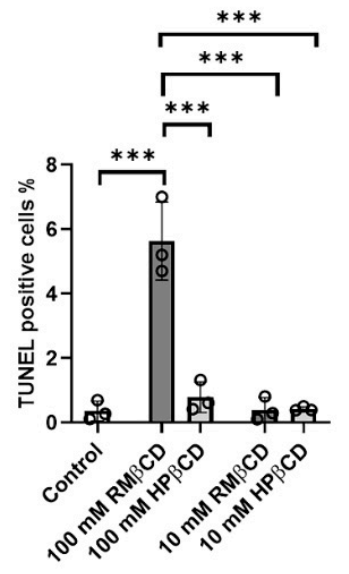

Inner retina

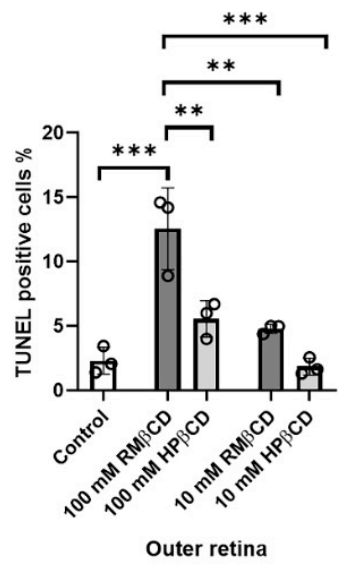

Figure 3. Cytotoxicity of $\beta$-derivatives of cyclodextrin in retina explant cultures. (a) Sections of retinal cultures to which different $C D$ solutions were applied; saline solution was used as the control. The terminal deoxynucleotidyl transferase dUTP nick end labeling (TUNEL) assay (red) was used to detect dying cells. DAPI (blue) was used as a nuclear counterstain. Cultures were derived from wild-type mice at postnatal day (P) 13. CDs were added at P15 and incubated with the cultures for a duration of $48 \mathrm{~h}$. ONL = outer nuclear layer, INL = inner nuclear layer, and GCL = ganglion cell layer. (b) Analysis of average TUNEL positive cells (\%) in both INL and ONL from cultures with different $\mathrm{CD}$ solutions and the control. Results represent the mean \pm SD for $n=3$ explant cultures per group. Statistical analysis was performed using one-way ANOVA with Tukey's multiple comparisons test $(\alpha=0.05)$ and asterisks represent the significant difference $\left(^{* *}=p \leq 0.01\right.$ and $\left.{ }^{* * *}=p \leq 0.001\right)$.

The higher toxicity of RM $\beta C D$ at both concentrations compared to HP $\beta C D$ may be due to various reasons. $\mathrm{RM} \beta C D$ is a modified $\beta C D$ where about two-thirds of the hydroxy groups have been replaced by methoxy groups, while in the case of HP $\beta C D$, only a few of the CD-hydroxyl groups have been substituted by 2-hydroxypropyl groups, which makes RM $\beta C D$ more lipophilic, with a $\log P$ value of $-6[12,35,36]$. The $\log P$ value for $\mathrm{HP} \beta C D$ is about -11 . The lipophilicity of the CDs clearly affects other properties, such as the solubilizing capacity, tissue irritating effect, hemolytic activity, and surface activity. The more lipophilic the compound, the easier it penetrates the cell layer, even though the permeability of CDs through biological membranes is negligible, as explained by Loftsson et al. [12], because of the size and hydrophilicity of the CD molecules.

Recently, it has been shown that RM $\beta C D$ can penetrate the epidermis and dermis of the human skin [37]. In addition, relatively high amounts of HP $\beta C D$ and dimethyl- $\beta$ cyclodextrin were absorbed via the rectum of rats and excreted into the urine, suggesting CD complexes may be absorbable through the rectal mucosa [38]. However, the latest 
findings regarding the endocytosis of CDs gave a whole new perspective of CDs being able to enter cells [33]. CD molecules can easily form complexes with natural hydrophobic molecules including the cellular components based on the host-guest interaction. Phospholipids are the preferred cellular target for $\alpha \mathrm{CD}$ and cholesterol for $\beta C D$ [39]. Because of this property, they have also been described to induce lysis of cell membranes by removal of membrane components such as cholesterol, phospholipids, and proteins [23,40,41].

Cholesterol is one of the major components of the cell membrane constituting $30 \%$ of total lipids and plays an important structural role in membrane stability [42]. Since $\beta C D$ has an affinity for cholesterol, this CD can induce the release of cellular cholesterol directly affecting the cell and biological barriers [40]. Consequently, the cholesterol content of the membranes can decrease thus affecting the function of the cell membrane and disrupting the barrier function of the cell layers [39]. Additionally, it was found that cholesterol extraction caused the destabilization of tight-junction protein complexes, which are localized in lipid rafts [39]. Methylated $\beta$-cyclodextrins tend to interact strongly with lipids [43,44], and there is a correlation between the cytotoxic effect and the cholesterol complexation properties of $\beta C D$ such that the higher complexation with cholesterol increases the toxicity to the cells [22].

In the retina, cholesterol represents $>98 \%$ of total sterols [45]. The stronger interaction of $\mathrm{CD}$ with the lipids/cholesterol in retinal cells can aid in more vigorous cell membrane destabilization and more cell death. Likewise, there are similar reports on Müller glia cells where the cholesterol status plays an important role. Low cholesterol is harmful to the retinal cells; hence, more cholesterol extraction by $\mathrm{RM} \beta \mathrm{CD}$ likely causes more toxicity [45]. This idea was further supported by our phase solubility studies of cholesterol with different $\beta$-cyclodextrin derivates (Figure 4).

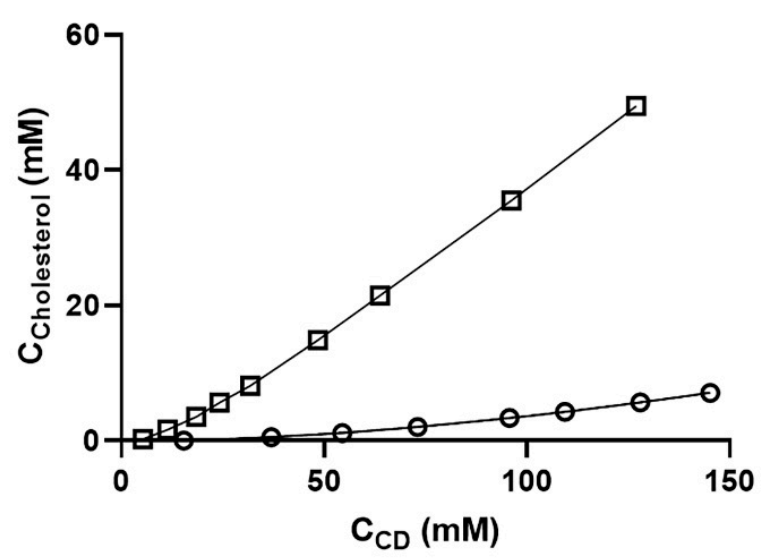

Figure 4. Phase-solubility diagrams of cholesterol in various aqueous $\beta$-cyclodextrin derivatives at room temperature. The diagram shows the $\mathrm{CD}$ concentration plotted against the cholesterol concentration. Overall, cholesterol was solubilized about five-fold more by RM $\beta C D$ than by HP $\beta C D$. Each point represents the mean of triplicate experiments. Key: $\mathrm{o}=\mathrm{HP} \beta C D$ and $\square=\mathrm{RM} \beta C D$.

Cholesterol was solubilized five times more effectively by RM $\beta C D$ compared to HP $\beta C D$ (Figure 4). Cholesterol had the highest affinity for the lipophilic RM $\beta C D$ but had a lower affinity for the very hydrophilic cyclodextrins like HP $\beta C D$. Cholesterol solubilization was also affected by the structure of the $\mathrm{CD}$ derivative, like the number and position of the methyl groups and the presence of ionic groups [22].

Similar results have been obtained when the toxicity of these CDs was tested on different cell lines. The cytotoxicity of methylated $\beta C D$ s was found to be very high in intestinal Caco-2 cell cultures, while substitution of the $\beta C D$ with hydroxyl groups drastically decreased the cytotoxicity [46]. However, in another study, HP $\beta C D$ presented no cytotoxicity up to $200 \mathrm{mM}$ on the same cell lines [22]. 
Furthermore, $\mathrm{RM} \beta \mathrm{CD}$ possesses surface-active properties $[47,48]$ and it even shows a detergent-like mechanism of lipid solubilization when interacting with lipid vesicles. Here, $\mathrm{RM} \beta C D$ was first adsorbed onto the vesicle surface, which was followed by RM $\beta C D$ partitioning from the aqueous medium into the phospholipid bilayers forming lipid-RM $\beta C D$ mixed assemblies and finally the lipid solubilization into micelle like aggregates [49]. The cells in the ONL are photoreceptor cells, and cholesterol is an important component of photoreceptor membranes, relevant for the cells function [50,51]. Hence, photoreceptors might suffer more from the cholesterol extraction capacity of the CDs, something that might be particularly relevant for the higher toxicity observed with RM $\beta C D$. Additionally, the cell death in the ONL might be exacerbated by an overall higher sensitivity of photoreceptors, when compared to INL cells.

\subsection{Fluorescent Microscopy of Fluorescently-Labeled Cyclodextrin Derivates to Study Cellular Uptake in Retinal Cultures}

Following this, we investigated the overall distribution of fluorescently-labeled CDs in the retina. To this end, RBITC-HP $\beta C D$, FITC-HP $\beta C D$, and FITC-RM $\beta C D$ were used and the fluorescent intensity in the inner and outer retina was quantified (Figure 5) and compared to the control specimen to account for auto-fluorescence coming from the tissue itself. No difference between FITC-labeled CDs was observed for the inner and outer retina, indicating that the $H P \beta C D$ and $R M \beta C D$ distribute similarly within the retina. Therefore, the difference in cytotoxicity between the two compounds was likely due to their respective effect on the cells, as discussed above, and not because of differences in the overall tissue distribution.

Some subtle differences between FITC-labeled CDs were observed. For FITC-HP $\beta C D$, a string-like structure was seen, spanning across the inner and outer retina. This was not as prominent in cultures where FITC-RM $\beta C D$ was applied (Figure 5a). This type of staining suggests that the CDs had partly been taken up by Müller glial cells.

When using a rhodamine-labeled CD, we observed an elevated signal in the retina. The signal-to-noise ratio was higher for RBITC-HP $\beta C D$ than for FITC-HP $\beta C D$ (Figure 5b,c). This allowed us to detect specific uptake in photoreceptors, which supported the result from the cytotoxicity analysis, where HP $\beta C D$ mainly killed cells in the outer retina.

However, these results should be taken with a grain of salt as the dye labelling could also have affected cell uptake. First of all, we did not observe the same Müller cell uptake in retinas with RBITC-HP $\beta C D$, compared with retinas with FITC-HP $\beta C D$. Since the rhodamine molecule is positively charged, the rhodamine-conjugated CDs might bind to negatively charged cell membranes and extracellular matrix elements, possibly facilitating cellular uptake. FITC and RBITC derivatives behave differently and are internalized by different processes. The labelling increases the molecular weight and may alter the properties of the parental CDs, while these still retain high water solubility and cannot cross the cell membrane by passive diffusion. However, there are reports suggesting that endocytosis was observed in fluorescent CDs as well [34]. Müller cells have the capacity to assemble and secrete lipoproteins which can be utilized by photoreceptors or inner retinal neurons, serving as an intraretinal source of cholesterol [52]. This could explain the Müller cell uptake of HP $\beta C D$.

While the fluorescent CDs do not behave exactly as their non-fluorescent form, these studies enhance the understanding of the behavior of labelled CD derivatives at the tissue level [53]. Together with the toxicity analysis, these results may be employed in further the development of CDs as drugs or drug carriers for the treatment of retinal diseases. 
(a)

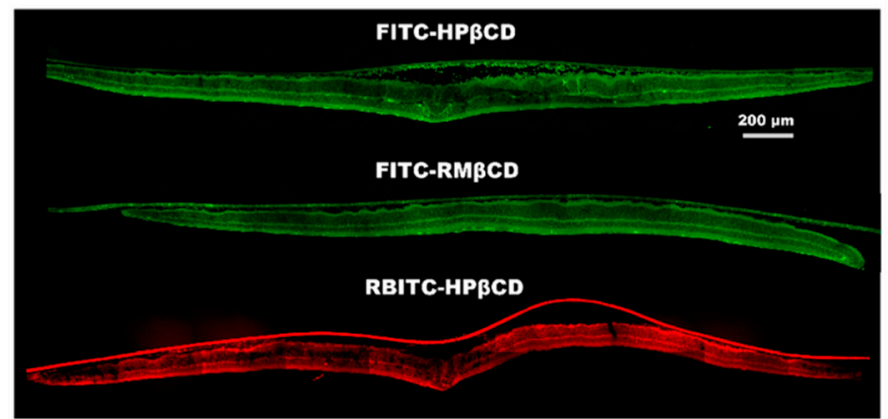

(b)

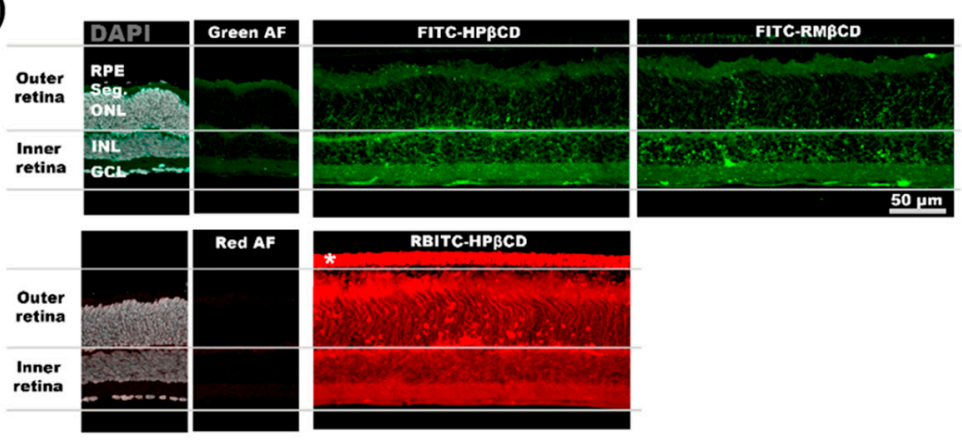

(c)

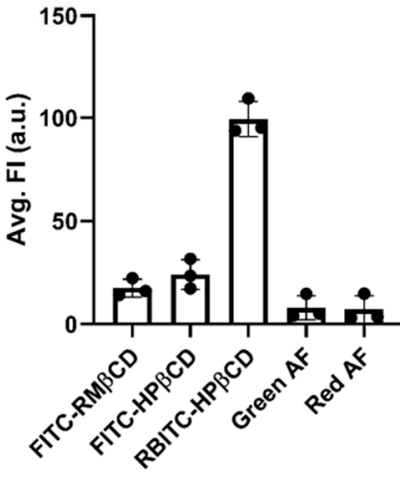

Inner Retina

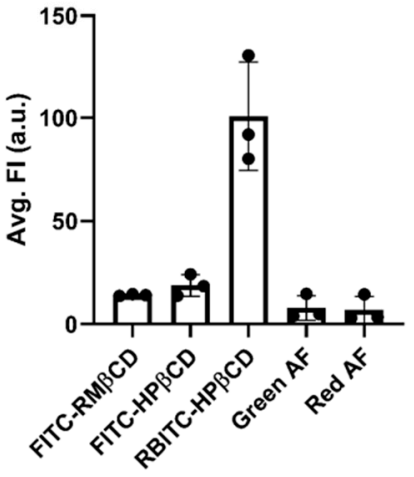

Outer retina

Figure 5. Uptake of fluorescently-labeled CDs in the retina explant culture. (a) Overview of tissue sections from wild type (WT) mice explant cultures to which three different fluorescently-labeled CDs were added to the side facing down in the image. (b) Close-up images of the sections were taken for an analysis of the fluorescent signal. Images from control sections (without added CDs) were used to measure the intensity of the red and green auto-fluorescence (AF) coming from the tissue itself. For this analysis, the outer retina is defined as the area from the outer nuclear layer $(\mathrm{ONL})$ to the retinal pigment epithelium (RPE), while the inner retina encompasses the area from the ganglion cell layer (GCL) to the inner nuclear layer (INL). Seg. = segments of the photoreceptors (inner and outer segment). * membrane on which the retinal explant was cultured. (c) Analysis of the average fluorescent intensity coming from either the inner or outer retina. For both inner and outer retina, a high signal was detected from RBITC-labeled CDs, while the signal was lower and similar for FITC-labeled CDs. Results represent the mean $\pm \operatorname{SD}$ for $n=3$, where $n$ is the number of animals.

\section{Materials and Methods}

\subsection{Materials}

Randomly methylated $\beta$-cyclodextrin (RM $\beta C D$, also referred to as RAMEB) with a degree of substitution (DS) of 12.6 (molecular weight, MW 1312) was purchased from Wacker Chemie (Munich, Germany), and cholesterol from Sigma Chemical Co. (St. Louis, MO, USA), while 2-hydroxypropyl- $\beta$-cyclodextrin (HP $\beta C D)$ with DS 4.2 (MW 1380) was 
kindly provided by Janssen Pharmaceutica, Belgium. The solubility of HP $\beta C D$ in water is $>600 \mathrm{mg} / \mathrm{mL}$, while that of $\mathrm{RM} \beta C D$ is $>500 \mathrm{mg} / \mathrm{mL}$ [1].

6-deoxy-6-[(5/6)-fluoresceinylthioureido]-RM $\beta C D, 6$-deoxy-6-[(5/6)-fluoresceinyl thioureido]-HP $\beta C D$ and 6-deoxy-6-[(5/6)-rhodaminylthioureido]-HP $\beta C D$ were kindly provided by CycloLab, Budapest, Hungary. Milli- $Q$ water and sterile saline solution were used for the preparation of $\mathrm{CD}$ solution and all other chemicals were commercially available products (Sigma-Aldrich, Saint Louis, MO, USA) of special reagent grade.

\subsection{Methods}

\subsubsection{Animals}

The $\mathrm{C} 3 \mathrm{H}$ wild-type mouse line was used in all studies [54]. Animals were used irrespective of gender and were housed with free access to food and water under standard white light with $12 \mathrm{~h} \mathrm{light/dark}$ cycles. They were sacrificed at postnatal day (P) 13 by $\mathrm{CO}_{2}$ asphyxiation, followed by cervical dislocation. All procedures were performed in accordance with $\S 4$ of the German law on animal protection and approved by the animal protection committee of the University of Tübingen (Einrichtung für Tierschutz, Tierärztlichen Dienst und Labortierkunde; Registration No. AK02/19M, 3 April 2019).

\subsubsection{Assessment of the Retinal Cytotoxicity of $\beta$-Cyclodextrin Derivatives}

Culturing of Organotypic Retinal Explant Cultures

To study the cytotoxicity of CDs on the retinal tissue, retinas from mice were isolated for culturing for an extended period of time. The detailed protocol is described elsewhere [55], but will be summarized here. Immediately after animal sacrifice, the eyes were enucleated and incubated for $5 \mathrm{~min}$ at room temperature (RT) in R16 serum-free culture medium (Gibco, Carlsbad, CA, USA). To promote the removal of the sclera and choroid, the eyes were transferred to a preheated $\left(37^{\circ} \mathrm{C}\right)$ solution of $0.12 \%$ proteinase $\mathrm{K}$ (MP Biomedicals, Illkirch-Grafenstaden, France) and incubated for $15 \mathrm{~min}$. Afterwards, the eyes were soaked in 1:4 mixtures of $10 \%$ FBS/medium to stop the protease reaction. The eyes were dissected under sterile conditions. The retina with the retinal pigment epithelium (RPE) attached was isolated and cultured on a Transwell membrane (polycarbonate, $0.4 \mu \mathrm{m}$ pore size, COSTAR, NY) with the RPE side facing down in a 6-well plate. Then, $1 \mathrm{~mL}$ complete medium (CM, R16 medium with supplements; detailed under [55]) was added to each well. The explants were allowed to recover from the explantation procedure in a sterile incubator $\left(37^{\circ} \mathrm{C}, 5 \% \mathrm{CO}_{2}\right)$ for $48 \mathrm{~h}$. The $\mathrm{CM}$ was exchanged every second day by removing $0.7 \mathrm{~mL}$ of the $\mathrm{CM}$ in the plate and adding $0.9 \mathrm{~mL}$ fresh $\mathrm{CM}$ to account for evaporation and conserve neuroprotective agents produced by the retinal culture. At P15, CD and saline solution were applied to the cultures for a $48 \mathrm{~h}$ incubation period. Here, $20 \mu \mathrm{L}$ of isotonic $\mathrm{CD}$ solutions (adjusted by $\mathrm{NaCl}$ ) was carefully placed on the top of the retina to cover the whole tissue. Either 10 or $100 \mathrm{mM} \mathrm{CD}$ was used. For fluorescently-tagged CD, $5 \mathrm{mM}$ was applied. Alternatively, a $0.9 \% \mathrm{NaCl}$ solution was added as a control. All solutions were passed through sterile filters (PES, $0.22 \mu \mathrm{m}$, Merck Millipore, Ireland) before being introduced to the culture.

Preparation of Retinal Tissue Sections

After the culturing of organotypic retinal explants with $\mathrm{CD}$ or saline, the cultures were fixed in a $4 \%$ paraformaldehyde/PBS solution for at least $45 \mathrm{~min}$. The explants were cryoprotected by introducing an incremental amount of sucrose to the well plate, i.e., $10 \%$ sucrose, $20 \%$ sucrose, and $30 \%$ sucrose for 10,20 , and $30 \mathrm{~min}$ (at RT), respectively. Afterwards, the area of the retina culture attached to the Transwell membrane was cut out with fine scissors, and the membrane piece was submerged in an embedding medium (Tissue-Tek O.C.T. Compound, Sakura Finetek Europe, Netherlands), followed by snap freezing in liquid nitrogen. The frozen specimens were sectioned on an NX50 cryostat (ThermoFisher, Waltham, MA) to produce $14 \mu \mathrm{m}$ thick sections on Superfrost Plus object 
slides (R. Langenbrinck, Emmendingen, Germany) used for direct imaging or further staining.

Assessing Cell Death in Retinal Sections Using the TUNEL Assay

A terminal deoxynucleotidyl transferase dUTP nick end labeling (TUNEL) assay was used to stain the nuclei with damaged (nick-end) DNA [56]. This was done to quantify the number of dying cells in retinal cultures after $C D$ or saline was applied to assess the cytotoxicity of the CDs. Firstly, microscopy slides with retinal sections were rehydrated with PBS. A proteinase K solution preheated to $37^{\circ} \mathrm{C}(0.21 \mu \mathrm{g} / \mathrm{mL}$, Tris-buffered saline (TBS) (Sigma-Aldrich, Saint Louis, MO, USA) was added and incubated for $5 \mathrm{~min}$ at $37^{\circ} \mathrm{C}$. After washing with TBS, a solution of ethanol/acetic acid was added and incubated for 5 min before washing. A blocking solution consisting of $1 \%$ bovine serum albumin, $10 \%$ normal goat serum, 3\% Triton-X (Sigma-Aldrich, Saint Louis, MO, USA), and 2.5\% fish gelatin in PBS was incubated on the sections ( $1 \mathrm{~h}, \mathrm{RT}$ ). A TUNEL reaction solution consisting of the enzyme solution and labeling solution from the In Situ Cell Death Detection Kit (TMR red, Product No. 12156792910, Sigma Aldrich) was prepared at a 1:9 ratio, diluted in blocking solution (1:1), and incubated with the slides at $37^{\circ} \mathrm{C}$ for $1 \mathrm{~h}$. The slides were washed with PBS, and a mounting medium with DAPI (Vectashield, Vector Laboratories, USA) was added. Samples were kept at $2-8{ }^{\circ} \mathrm{C}$ for at least $30 \mathrm{~min}$ before imaging with fluorescent microscopy (Axio Imager Z2 ApoTome, Carl Zeiss Microscopy GmbH), using a CCD camera with a $20 \times$ objective. Ex./Em. of $548 / 561 \mathrm{~nm}$ was used to detect TUNEL labeling at random locations of the section. Image acquisition was conducted by recording z-stacks, each with 10 images $1 \mu \mathrm{m}$ apart. Values such as the exposure time for the red (TUNEL) channel, binning, and brightness/contrast of each image were kept consistent. To quantify the number of dying cells, in either the inner or outer nuclear layer in the tissue section, the following equation was used:

$$
\text { TUNEL positive cells }(\%)=\frac{\# \text { AUNEL positive nuclei }}{\text { Area of layer / Average area of nuclei }} \cdot 100 \% \text {. }
$$

To analyze the statistical significance within the dataset, one-way ANOVA with Tukey's multiple comparisons test $(\alpha=0.05)$ was performed using GraphPad Prism 8.

Determining the Retinal Uptake of Fluorescently-Labeled $\beta$-Cyclodextrin

Fluorescently-labeled CD (FITC-HP $\beta C D$, RBITC-HP $\beta C D$, and FITC-RM $\beta C D$ ) was added to organotypic retinal explant cultures, as described previously. Slides with retinal tissue sections were rehydrated in PBS for 10 min before mounting medium with DAPI (Vectashield, Vector Laboratories, USA) was added. Images were recorded with fluorescent microscopy, as described above. A green (Ex./Em. 493/513) and red (Ex./Em. 558/575) channel were used to detect the fluorescein or rhodamine labeling, respectively. Image acquisition was conducted by recording z-stacks, each with 14 images $1 \mu \mathrm{m}$ apart. Values such as the exposure time for the green and red channel, binning, and brightness/contrast of each image were kept consistent. Sections from the saline-treated retinas were imaged using the same parameters to determine the level of green and red auto-fluorescence from the cultures. Alternatively, tile pictures showing the entire retinal section were recorded by stitching together adjacent projected z-stacks in the image acquisition software (ZEN 2.6, Carl Zeiss Microscopy GmbH).

\subsubsection{Particle Size Measurement \\ Nano Sight Wave}

The laser-based light scattering analysis of $\mathrm{CD}$ particles was performed with Nano Sight NS300 (Malvern, Worcestershire, UK), fitted with an O-ring top-plate. Nanoparticle tracking analysis (NTA) software was used to capture images and process data, representing the concentration, size distribution, and intensity of particles in the sample. Sample measurement was done in static mode using a capture time of $60 \mathrm{~s}$ and five repeats. The 
camera level was adjusted to 11 so that all particles were visible. The same camera level was used for all the samples. A suitable detection level was selected for data analysis to limit the detection of non-particles and was between levels 4 and 12. The result for each sample was based on the average of five measurements obtained from the NTA and represented by the average particle concentration, average particle size (i.e., mean size), and mode size (i.e., the size that displays the highest peak).

Transmission Electron Microscopy (TEM) Analysis

The size and morphology of the CD in an aqueous solution were evaluated by using Model JEM-1400 Transmission Electron Microscopy (JEOL, Tokyo, Japan). The negative staining technique was utilized. Firstly, a small amount of clear CD solution $(3 \mu \mathrm{L})$ was dropped on a 300 -mesh coated grid and dried at $37-40{ }^{\circ} \mathrm{C}$ for one hour. Then, a drop of centrifuged $4 \% w / v$ uranyl acetate $(26 \mu \mathrm{L})$ was added to the loaded grid. After 6 min of staining, the sample was dried overnight at room temperature. Finally, the stained grid was placed in the sample holder and inserted into the microscope.

\subsubsection{Phase-Solubility Studies}

The phase-solubility studies of cholesterol were performed by dissolving cholesterol $(20 \mathrm{mg} / \mathrm{mL})$ in methylene chloride, followed by solvent evaporation $(0.3 \mathrm{~mL}$ per vial $)$ under a flow of nitrogen in cylindrical vials. This left a very thin layer of cholesterol on the inner surface of the vials. Aqueous CD solutions were added to the vials, which were tightly sealed and heated in an autoclave $\left(121^{\circ} \mathrm{C}\right.$ for $\left.20 \mathrm{~min}\right)$ [57]. The vials were opened after equilibrating them at room temperature overnight and a small amount of solid cholesterol was added to each vial, which were again allowed to equilibrate at room temperature for an additional 6 days. The seeding with cholesterol was performed to reduce the possibility of complications caused by differences in the solid-state of cholesterol. Finally, the aqueous cholesterol suspensions were filtered through a $0.45 \mu \mathrm{m}$ nylon membrane filter, and the filtrate was analyzed using high-pressure liquid chromatography (HPLC).

Quantitative determination of cholesterol was performed on a reversed-phase HPLC system from Merck-Hitachi (Darmstadt, Germany) consisting of an L 4250 UV-Vis detector operated at $203 \mathrm{~nm}, \mathrm{~L} 6200$ A Intelligent pump, AS-2000A Autosampler, D-2500 Cromato-Integrator, and Phenomex Luna (Cheshire, UK) $5 \mu \mathrm{m}$ C18 reversed-phase column $(150 \times 4.6 \mathrm{~mm})$. The mobile phase consisted of methanol, acetonitrile, isopropyl alcohol, and tetrahydrofuran (50:25:25:0.1).

Author Contributions: Conceptualization, M.P.; methodology, M.P. and G.C.; data curation, M.P., T.L. and G.C.; formal analysis, M.P. and G.C.; investigation; M.P. and G.C.; writing-original draft preparation, M.P.; writing, reviewing, and editing, M.P., G.C., F.P.-D. and T.L.; supervision, F.P.-D. and T.L.; funding acquisition, F.P.-D. and T.L. All authors have read and agreed to the published version of the manuscript.

Funding: This work was financially supported by the European Union grant no. MSCA-ITN-2017765441 (transMed); the German Research Council (DFG) grant no. PA1751/10-1; and the Faculty of Pharmaceutical Sciences, University of Iceland.

Data Availability Statement: No data reported.

Acknowledgments: The authors gratefully acknowledge CycloLab, Budapest, Hungary, for providing us with the fluorescent cyclodextrins used in the study.

Conflicts of Interest: The authors declare no conflict of interest.

Sample Availability: Samples of the compounds are not available from the authors. 


\section{References}

1. Loftsson, T.; Jarho, P.; Másson, M.; Järvinen, T. Cyclodextrins in drug delivery. Expert Opin. Drug Deliv. $2005,2,335-351$. [CrossRef]

2. Loftsson, T.; Björnsdóttir, S.; Pálsdóttir, G.; Bodor, N. The effects of 2-hydroxypropyl- $\beta$-cyclodextrin on the solubility and stability of chlorambucil and melphalan in aqueous solution. Int. J. Pharm. 1989, 57, 63-72. [CrossRef]

3. Stella, V.J.; He, Q. Cyclodextrins. Toxicol. Pathol. 2008, 36, 30-42. [CrossRef]

4. Questions and Answers on Cyclodextrins Used as Excipients in Medicinal Products for Human Use. Available online: https: / / www.ema.europa.eu/en/documents/report/cyclodextrins-used-excipients-report-published-support-questionsanswers-cyclodextrins-used_en.pdf (accessed on 11 February 2021).

5. Zhang, D.; Lv, P.; Zhou, C.; Zhao, Y.; Liao, X.; Yang, B. Cyclodextrin-based delivery systems for cancer treatment. Mater. Sci. Eng. C 2019, 96, 872-886. [CrossRef] [PubMed]

6. Carneiro, S.B.; Duarte, F.; Ílary, C.; Heimfarth, L.; Quintans, J.D.S.S.; Quintans-Júnior, L.J.; Júnior, V.F.D.V.; Neves de Lima, Á.A Cyclodextrin-Drug Inclusion Complexes: In Vivo and In Vitro Approaches. Int. J. Mol. Sci. 2019, 20, 642. [CrossRef] [PubMed]

7. Saokham, P.; Muankaew, C.; Jansook, P.; Loftsson, T. Solubility of Cyclodextrins and Drug/Cyclodextrin Complexes. Molecules 2018, 23, 1161. [CrossRef] [PubMed]

8. Conceicao, J.; Adeoye, O.; Cabral-Marques, H.M.; Lobo, J.M.S. Cyclodextrins as Drug Carriers in Pharmaceutical Technology: The State of the Art. Curr. Pharm. Des. 2018, 24, 1405-1433. [CrossRef]

9. Muankaew, C.; Loftsson, T. Cyclodextrin-Based Formulations: A Non-Invasive Platform for Targeted Drug Delivery. Basic Clin Pharmacol. Toxicol. 2018, 122, 46-55. [CrossRef]

10. Loftsson, T.; Duchene, D. Cyclodextrins and their pharmaceutical applications. Int. J. Pharm. 2007, 329, 1-11. [CrossRef]

11. Saokham, P.; Loftsson, T. g-Cyclodextrin. Int. J. Pharm. 2017, 516, $278-292$.

12. Jansook, P.; Ogawa, N.; Loftsson, T. Cyclodextrins: Structure, physicochemical properties and pharmaceutical applications. Int. J. Pharm. 2018, 535, 272-284. [CrossRef] [PubMed]

13. Stella, V.J.; Rajewski, R.A. Sulfobutylether- $\beta$-cyclodextrin. Int. J. Pharm. 2020, 583, 119396. [CrossRef]

14. Friedrich, S.; Cheng, Y.-L.; Saville, B. Drug distribution in the vitreous humor of the human eye: The effects of intravitreal injection position and volume. Curr. Eye Res. 1997, 16, 663-669. [CrossRef] [PubMed]

15. Varela-Fernández, R.; Díaz-Tomé, V.; Luaces-Rodríguez, A.; Conde-Penedo, A.; García-Otero, X.; Luzardo-Álvarez, A.; FernándezFerreiro, A.; Otero-Espinar, F.J. Drug Delivery to the Posterior Segment of the Eye: Biopharmaceutic and Pharmacokinetic Considerations. Pharmaceutics 2020, 12, 269. [CrossRef] [PubMed]

16. Ashton, P. Intraocular Drug Delivery; Jaffe, G.J., Ashton, P., Pearson, P.A., Eds.; Taylor \& Francis: New York, NY, USA, 2006; pp. $1-25$.

17. Chaudhari, P.; Ghate, V.M.; Lewis, S.A. Supramolecular cyclodextrin complex: Diversity, safety, and applications in ocular therapeutics. Exp. Eye Res. 2019, 189, 107829. [CrossRef] [PubMed]

18. Leclercq, L. Interactions between cyclodextrins and cellular components: Towards greener medical applications? Beilsteinj. Org. Chem. 2016, 12, 2644-2662. [CrossRef]

19. Loftsson, T.; Stefánsson, E. Cyclodextrins in ocular drug delivery: Theoretical basis with dexamethasone as a sample drug. J. Drug Deliv. Sci. Technol. 2007, 17, 3-9. [CrossRef]

20. Castro-Balado, A.; Mondelo-García, C.; Zarra-Ferro, I.; Fernández-Ferreiro, A. New ophthalmic drug delivery systems. Farm. Hosp. 2020, 44, 149-157. [CrossRef] [PubMed]

21. Moiseev, R.V.; Morrison, P.W.J.; Steele, F.; Khutoryanskiy, V.V. Penetration Enhancers in Ocular Drug Delivery. Pharmaceutics 2019, 11, 321. [CrossRef] [PubMed]

22. Kiss, T.; Fenyvesi, F.; Bácskay, I.; Váradi, J.; Fenyvesi, É.; Iványi, R.; Szente, L.; Tósaki, Á.; Vecsernyés, M. Evaluation of the cytotoxicity of beta-cyclodextrin derivatives: Evidence for the role of cholesterol extraction. Eur. J. Pharm. Sci. 2010, 40, 376-380. [CrossRef]

23. Irie, T.; Uekama, K. Pharmaceutical applications of cyclodextrins 3. Toxicological issues and safety evaluation. J. Pharm. Sci. 1997, 86, 147-162. [CrossRef] [PubMed]

24. Vecsernyés, M.; Fenyvesi, F.; Bácskay, I.; Deli, M.A.; Szente, L. Fenyvesi, Éva Cyclodextrins, Blood-Brain Barrier, and Treatment of Neurological Diseases. Arch. Med. Res. 2014, 45, 711-729. [CrossRef]

25. Nociari, M.M.; Lehmann, G.L.; Bay, A.E.P.; Radu, R.A.; Jiang, Z.; Goicochea, S.; Schreiner, R.; Warren, J.D.; Shan, J.; De Beaumais, S.A.; et al. Beta cyclodextrins bind, stabilize, and remove lipofuscin bisretinoids from retinal pigment epithelium. Proc. Natl. Acad. Sci. USA 2014, 111, E1402-E1408. [CrossRef] [PubMed]

26. Racz, B.; Varadi, A.; Kong, J.; Allikmets, R.; Pearson, P.G.; Johnson, G.; Cioffi, C.L.; Petrukhin, K. A non-retinoid antagonist of retinol-binding protein 4 rescues phenotype in a model of Stargardt disease without inhibiting the visual cycle. J. Biol. Chem. 2018, 293, 11574-11588. [CrossRef] [PubMed]

27. Kam, J.H.; Lynch, A.; Begum, R.; Cunea, A.; Jeffery, G. Topical cyclodextrin reduces amyloid beta and inflammation improving retinal function in ageing mice. Exp. Eye Res. 2015, 135, 59-66. [CrossRef]

28. El-Darzi, N.; Mast, N.; Petrov, A.M.; Pikuleva, I.A. 2-Hydroxypropyl- $\beta$-cyclodextrin reduces retinal cholesterol in wild-type and Cyp27a1-/-Cyp46a1 ${ }^{-/-}$mice with deficiency in the oxysterol production. Br. J. Pharm. 2020, 1-15. [CrossRef] [PubMed] 
29. Messner, M.; Kurkov, S.V.; Jansook, P.; Loftsson, T. Self-assembled cyclodextrin aggregates and nanoparticles. Int. J. Pharm. 2010, 387, 199-208. [CrossRef]

30. Loftsson, T.; Saokham, P.; Couto, A.R.S. Self-association of cyclodextrins and cyclodextrin complexes in aqueous solutions. Int. J. Pharm. 2019, 560, 228-234. [CrossRef]

31. Loftsson, T. Cyclodextrins in Parenteral Formulations. J. Pharm. Sci. 2021, 110, 654-664. [CrossRef]

32. Do, T.T.; Van Hooghten, R.; Mooter, G.V.D. A study of the aggregation of cyclodextrins: Determination of the critical aggregation concentration, size of aggregates and thermodynamics using isodesmic and K2-K models. Int. J. Pharm. 2017, 521, 318-326. [CrossRef]

33. Rosenbaum, A.I.; Zhang, G.; Warren, J.D.; Maxfield, F.R. Endocytosis of beta-cyclodextrins is responsible for cholesterol reduction in Niemann-Pick type C mutant cells. Proc. Natl. Acad. Sci. USA 2010, 107, 5477-5482. [CrossRef]

34. Réti-Nagy, K.; Malanga, M.; Fenyvesi, É.; Szente, L.; Vámosi, G.; Váradi, J.; Bácskay, I.; Fehér, P.; Ujhelyi, Z.; Róka, E.; et al. Endocytosis of fluorescent cyclodextrins by intestinal Caco-2 cells and its role in paclitaxel drug delivery. Int. J. Pharm. 2015, 496, 509-517. [CrossRef]

35. Řezanka, M. Synthesis of substituted cyclodextrins. Environ. Chem. Lett. 2018, 17, 49-63. [CrossRef]

36. Szente, L.; Szejtli, J. Highly soluble cyclodextrin derivatives: Chemistry, properties, and trends in development. Adv. Drug Deliv. Rev. 1999, 36, 17-28. [CrossRef]

37. Weisse, S.; Perly, B.; Creminon, C.; Ouvrard-Baraton, F.; Djedai'Ni-Pilard, F. Enhancement of vitamin A skin absorption by cyclodextrins. J. Drug Deliv. Sci. Technol. 2004, 14, 77-86. [CrossRef]

38. Matsuda, H.; Arima, H. Cyclodextrins in transdermal and rectal delivery. Adv. Drug Deliv. Rev. 1999, 36, 81-99. [CrossRef]

39. Haimhoffer, Á.; Rusznyák, Á.; Réti-Nagy, K.; Vasvári, G.; Váradi, J.; Vecsernyés, M.; Bácskay, I.; Fehér, P.; Ujhelyi, Z.; Fenyvesi, F.; et al. Cyclodextrins in Drug Delivery Systems and Their Effects on Biological Barriers. Sci. Pharm. 2019, 87, 33. [CrossRef]

40. Kilsdonk, E.P.C.; Yancey, P.G.; Stoudt, G.W.; Bangerter, F.W.; Johnson, W.J.; Phillips, M.C.; Rothblat, G.H. Cellular Cholesterol Efflux Mediated by Cyclodextrins. J. Biol. Chem. 1995, 270, 17250-17256. [CrossRef]

41. Ohtani, Y.; Irie, T.; Uekama, K.; Fukunaga, K.; Pitha, J. Differential effects of $\alpha$-, $\beta$ - and $\gamma$-cyclodextrins on human erythrocytes. Eur. J. Biochem. 1989, 186, 17-22. [CrossRef]

42. Krause, M.R.; Regen, S.L. The Structural Role of Cholesterol in Cell Membranes: From Condensed Bilayers to Lipid Rafts. Acc. Chem. Res. 2014, 47, 3512-3521. [CrossRef]

43. Yancey, P.G.; Rodrigueza, W.V.; Kilsdonk, E.P.C.; Stoudt, G.W.; Johnson, W.J.; Phillips, M.C.; Rothblat, G.H. Cellular Cholesterol Efflux Mediated by Cyclodextrins: DEMONSTRATION OF KINETIC POOLS AND MECHANISM OF EFFLUX*. J. Biol. Chem. 1996, 271, 16026-16034. [CrossRef] [PubMed]

44. Irie, T.; Wakamatsu, K.; Arima, H.; Aritomi, H.; Uekama, K. Enhancing effects of cyclodextrins on nasal absorption of insulin in rats. Int. J. Pharm. 1992, 84, 129-139. [CrossRef]

45. Lakk, M.; Yarishkin, O.; Baumann, J.M.; Iuso, A.; Križaj, D. Cholesterol regulates polymodal sensory transduction in Müller glia. Glia 2017, 65, 2038-2050. [CrossRef] [PubMed]

46. Roka, E.; Ujhelyi, Z.; Deli, M.; Bocsik, A.; Fenyvesi, E.; Szente, L.; Fenyvesi, F.; Vecsernyés, M.; Váradi, J.; Fehér, P.; et al. Evaluation of the Cytotoxicity of $\alpha$-Cyclodextrin Derivatives on the Caco-2 Cell Line and Human Erythrocytes. Molecules 2015, 20, 20269-20285. [CrossRef] [PubMed]

47. Cserháti, T.; Szejtli, J. Surfactant activity of methylated b-cyclodextrins. Tenside Deterg. 1985, 22, $237-238$.

48. Azarbayjani, A.F.; Lin, H.; Yap, C.W.; Chan, Y.W.; Chan, S.Y. Surface tension and wettability in transdermal delivery: A study on the in-vitro permeation of haloperidol with cyclodextrin across human epidermis. J. Pharm. Pharmacol. 2010, 62, 770-778. [CrossRef] [PubMed]

49. Boulmedarat, L.; Bochot, A.; Lesieur, S.; Fattal, E. Evaluation of buccal methyl-beta-cyclodextrin toxicity on human oral epithelial cell culture model. J. Pharm. Sci. 2005, 94, 1300-1309. [CrossRef]

50. Mauch, D.H. CNS Synaptogenesis Promoted by Glia-Derived Cholesterol. Science 2001, 294, 1354-1357. [CrossRef] [PubMed]

51. Fliesler, S.J.; Vaughan, D.K.; Jenewein, E.C.; Richards, M.J.; Nagel, B.A.; Peachey, N.S. Partial Rescue of Retinal Function and Sterol Steady-State in a Rat Model of Smith-Lemli-Opitz Syndrome. Pediatr. Res. 2007, 61, 273-278. [CrossRef]

52. Rao, S.R.; Fliesler, S.J. Cholesterol homeostasis in the vertebrate retina: Biology and pathobiology. J. Lipid Res. 2021, 100057. [CrossRef]

53. Váradi, J.; Hermenean, A.; Gesztelyi, R.; Jeney, V.; Balogh, E.; Majoros, L.; Malanga, M.; Fenyvesi, É.; Szente, L.; Bácskay, I.; et al. Pharmacokinetic Properties of Fluorescently Labelled Hydroxypropyl-Beta-Cyclodextrin. Biomolecules 2019, 9, 509. [CrossRef]

54. Sanyal, S.; Bal, A.K. Comparative light and electron microscopic study of retinal histogenesis in normal and rd mutant mice. Z. Anat. Entwickl. 1973, 142, 219-238. [CrossRef]

55. Belhadj, S.; Tolone, A.; Christensen, G.; Das, S.; Chen, Y.; Paquet-Durand, F. Long-Term, Serum-Free Cultivation of Organotypic Mouse Retina Explants with Intact Retinal Pigment Epithelium. J. Vis. Exp. 2020, 165, e61868. [CrossRef]

56. Loo, D.T. In Situ Detection of Apoptosis by the TUNEL Assay: An Overview of Techniques. Pericytes 2010, 682, 3-13. [CrossRef]

57. Loftsson, T.; Másson, M.; Sigurjónsdóttir, J.F. Methods to enhance the complexation efficiency of cylodextrins. S.T.P. Pharma Sci. $1999,9,237-242$. 